\title{
Model characteristics of physical, functional readiness, psycho-emotional state and competitive activity of weightlifters in dynamics of four years
}

\author{
Zinaida Kuznetsova ${ }^{1}$, Ilsiyar Mutaeva ${ }^{2}$, Ilyas Ibragimov $^{3 *},{\text { Naziya } \text { Islamova }^{4} \text {, Alfiya Safina }}^{4}$ \\ ${ }^{1}$ Chaykovskiy State Institute of Physical Culture, 617764, Chaykovskiy, Russia \\ ${ }^{2}$ Yelabuga Institute of Kazan (Volga region) Federal University, 423600, Yelabuga, Russia \\ ${ }^{3}$ Tyumen Higher Military -Engineering Command School (military Institute), 625001, Tyumen, Russia \\ ${ }^{4}$ Naberezhnye Chelny branch of the University of Management "TISBI", 423806, Naberezhnye Chelny, Russia
}

\begin{abstract}
The article considers the indices of studying all sides of readiness among weightlifters for model characteristics formation according to kinds of training. The results of the held research works in dynamics of several years help to choose the average values depending on weightlifters' level of readiness, experience and age. The research work examined the cadets, who go in for kettlebell lifting at Tyumen Higher Military -Engineering Command School. We defined the level of weightlifters' physical, functional, psycho-emotional readiness, working capacity and the indices of competitive activity. We analyzed four years of sports training among weightlifters. The article defines model values of the studied indices within the range of their deviations in the studied groups. The indices of the competitive exercise are distributed as phase, advanced and etalon model values. We substantiated the necessity to study model characteristics as the base for an effective training process correction at all stages of training. The held analysis helps to reveal that during recent years technical indices significantly increased. It proves the increased functional abilities of highly-qualified weightlifters, their physical readiness and the attention paid by coaches to this side of sports training.
\end{abstract}

\section{Introduction}

The most important index of sports training system effective work in weightlifters is the dynamics of their physical, functional, psycho-emotional readiness, working capacity and also aerobic productivity. Model characteristics study in the system of a long-term training among weightlifters can be the base of a complex macro cycle of training correction, demonstrated during competitive activity. From stage to stage we see the work, directed toward weightlifters' physical working capacity and aerobic productivity increase.

Scientific-methodical literature analysis concerning the problem of developing physical, functional, psychoemotional readiness, working capacity and weightlifters' functional state in the system of a long-term sports training showed that the effectiveness of the methodology creation, first of all, depends on taking into account model characteristics of all kinds of readiness.

Modern kettlebell lifting is characterized by a steady increase of competitive activity tension. It demands not only the increase of technical mastery, but also physical-functional, technical and psychological readiness of athletes $[4,5,6,7,8,11,13]$.

Some authors, who studied the questions of weightlifters' training process improvement, consider the importance of physical training a key part in physical working capacity increase and the effectiveness of competitive activity improvement $[1,2]$.

The specialists underline that the effectiveness of weightlifters' physical training increases using different variants of the training methodology, directed toward their results convergence to model values. They characterize competitive activity of weightlifters [3].

During the process of training at the stage of sportsmanship improvement taking into consideration all kinds of training we defined functional training with the necessity to achieve model level of competitive activity parameters, physical, functional and psycho-emotional readiness by an athlete.

Thus, model characteristics of all kinds of training creation in weightlifters, the profiles of readiness creation would help to improve the quality of competitive activity parameters demonstration.

\footnotetext{
${ }^{*}$ Corresponding author: i-i-n@inbox.ru
} 


\section{Materials and methods}

We realized scientific-methodical literature analysis. It considers the questions of effectiveness increase of different kinds of training in weightlifters. On the basis of studying all sides of readiness among weightlifters we created model characteristic of competitive, physical, functional and psycho-emotional readiness.

Cadets of military-engineering specialty (22 cadets) took part in the research on the basis of Tyumen Higher Military -Engineering Command School (Military Institute, Russia). They went in for kettlebell lifting.

For weightlifters' general state of an organism characterization we defined general physical working capacity using two loads of different power. For the results of physical working capacity $\left(\mathrm{PWC}_{170}\right)$ receiving we used the methodology by V.L. Karpman with other authors [9]. The indices of maximal oxygen consumption (MOC) were defined taking into account $\mathrm{PWC}_{170}$ indices according to the following formula: $\mathrm{MOC}=\mathrm{PWC}_{170} \mathrm{x} 1.7+1240$. In $\mathrm{PWC}_{170}$ study we used bicycle ergometer of Proteus PEC-4255 type. HR indices were set with the help of Polar RC3 GPS (Germany) watch. Maximal endurance index was defined according to the formula, where maximal endurance index $(\mathrm{MEI})=\mathrm{WMax} / \mathrm{BSA}$, WMax - maximal power of the load (W or $\mathrm{kgm} / \mathrm{min})$, BSA - body surface area [10].

The indices of psycho-emotional state were defined using the methodology of activatiometer «AT-9K», Russia (according to Yu.A. Tsagarelli, 2004). We studied the accuracy of reaction to a moving object; strength and weakness of nervous system coefficient; sense of tempo coefficient; movements coordination coefficient; general index of motor memory [12].

\section{Results and discussion}

The main ways of physical working capacity increase in weightlifters are the following: general and special physical, technical and psychological readiness increase. In this case the indices of functional state and functional abilities of an organism are very important. They characterize the state of locomotor apparatus, nervous-muscle system and central nervous system.

In the system of physical training of weightlifters it becomes important to develop such physical qualities as speedpower oriented qualities and strength, speed abilities and quickness, general and special endurance, coordinating abilities and dexterity, flexibility and mobility in joints. All this, first of all, is the guarantee of a high level of physical and functional readiness.

Further we present model characteristics of physical readiness and physical working capacity in weightlifters, created taking into account four years of performances during the competitions. It is mentioned that the demands of a competitive exercise of quicker tempo increases each year. The desire to achieve model values of readiness in a quicker tempo leads to adaptation violation and over-training state of weightlifters.

Table 1 presents model characteristics of physical and functional readiness of weightlifters in the dynamics of 4 years.

Table 1. Model characteristics of physical and functional readiness among weightlifters in the dynamics of 4 years

\begin{tabular}{|l|l|c|c|c|c|}
\hline \multirow{2}{*}{ oo } & Test exercises of physical and & \multicolumn{3}{|c|}{ Model characteristics according to the years of training } \\
\cline { 3 - 5 } & & & & & \\
functional testing & & 2016 & 2017 & 2018 & 2019 \\
\hline 1 & 100 m running, (s) & $12,8-13,5$ & $12,9-13,4$ & $12,9-13,7$ & $12,8-13,5$ \\
\hline 2 & 3000 m running, (s) & $640,25-650$ & $660-670$ & 680, & $680-690$ \\
\hline 3 & Chin-up, (quantity) & $15-17$ & $16-17$ & $16-18$ & $17-19$ \\
\hline 4 & Kettle ball holding, (s) & $199-200$ & $200-202$ & $203-205$ & $207-209$ \\
\hline 5 & Standing jump, (cm) & $225-227$ & $225-230$ & $235-240$ & $241-250$ \\
\hline 6 & Hands dislocation, (cm) & $63-64$ & $64-65$ & $66-67$ & $68-7-$ \\
\hline 7 & Pushing-off, (quantity) & $35-36$ & $37-38$ & $45-46$ & $51-55$ \\
\hline 8 & PWC 170, kg/min & $1345-1400$ & $1455-1460$ & $1456-1470$ & $1556-1570$ \\
\hline 9 & MOC, l/min & $57-58$ & $58-59$ & $64-65$ & $67-68$ \\
\hline 10 & MEI, c.u. & $399-400$ & $445-447$ & $456-458$ & $469-470$ \\
\hline
\end{tabular}

During 4 years we analyzed the protocols of physical readiness and physical working capacity. The held analysis helped to define the fluctuations range of the studied indices. The received indices after a thorough analysis were presented as the model ones.

The presented model values depending on the stages of training in weightlifters helped to introduce correction of the used training means. They are the following: the ratio of GPT (general physical training) and SPT (special physical training) in general preparatory and special preparatory stages, making the ratio 20 to $60 \%$ by the competitive stage.

Table 2 presents model characteristics of psycho-emotional state of weightlifters.

Table 2. Model characteristics of weightlifters' psycho-emotional state

\begin{tabular}{|l|l|c|c|c|c|}
\hline \multirow{2}{*}{$№$} & Test exercises and functional tests & \multicolumn{4}{|c|}{ Model characteristics according to the years of training } \\
\cline { 3 - 6 } & & 2016 & 2017 & 2018 & 2019 \\
\hline 1 & Accuracy of reaction to a moving & $33-32$ & $32-30$ & $29-28$ & $28-25$ \\
\hline
\end{tabular}




\begin{tabular}{|l|l|c|c|c|c|}
\hline & object & & & \\
\hline 2 & Sense of tempo coefficient & $3-2,5$ & $2,4-2,2$ & $2,1-1,9$ & $1,9-1,7$ \\
\hline 3 & $\begin{array}{l}\text { Coordination of movements } \\
\text { coefficient }\end{array}$ & $12-11$ & $11-10$ & $10-9$ & $9-7$ \\
\hline 4 & General index of motor memory & $11--10$ & $10-9$ & $9-8$ & $8-6$ \\
\hline
\end{tabular}

Table 2 presents model characteristics of weightlifters according to the indices of psycho-emotional state. During 4 years the indices in highly-qualified weightlifters only improved.

Table 3 presents the examples of weightlifters' model characteristics of competitive activity by the example of competitive exercise.

Table 3. Model characteristics of weightlifters' competitive activity by the example of a competitive exercise

\begin{tabular}{|l|c|c|c|}
\hline \multirow{2}{*}{$\begin{array}{l}\text { Competitive } \\
\text { exercises }\end{array}$} & Stage & Podel indices & Etalon \\
\cline { 2 - 4 } & $113-117,9$ & $118-119,9$ & $120-130$ \\
\hline Burst & $63-64,9$ & $65-66,9$ & $67-70$ \\
\hline Push & $180-189,9$ & $190-192,9$ & $193-195$ \\
\hline $\begin{array}{l}\text { Sum of double- } \\
\text { event }\end{array}$ & & \\
\hline
\end{tabular}

Exemplary model characteristics of weightlifters' competitive activity are given taking into account the results analysis of several years. They reflect the effectiveness of weightlifters' competitive activity by the example of the stage modeling. Perspective model of readiness reflects the effectiveness of weightlifters' performances in important starts. Etalon model is the ambition of each weightlifter. Such kind of model characteristics gradation, in the opinion of many specialists, helps to select effectively the best weightlifters.

The presented exercises indirectly reflect technical-tactical readiness of weightlifters.

Complex estimation of weightlifters' readiness indices in the targeting program of training within the Olympic cycle would help to develop the range of model indices. They would help to correct the training process of weightlifters, taking into account the tempo of their approach to model values. At a modern stage of kettlebell lifting development the best alternative of the training improvement system, model indices of all kinds of training use is a targeting program for a yearly cycle of training.

\section{Conclusions}

Thus, special urgency gains model characteristics creation of all kinds of training in weightlifters. Complex study of all sides of training in weightlifters helped to create a targeting program of training correction. It includes the following:

- algorithm of different means of training correction, directed toward a complex development of important physical qualities, taking into account the specificity of a kind of sport;

- methodology of technical and tactical training development;

- methodology of functional training development;

- methodology of weightlifters' psycho-emotional state development;

- the importance of all kinds of training increase;

- the range widening of competitive effectiveness increase in weightlifters.

\section{References}

1. A.A. Anasenko, Materials of scientific-practical conference (Moscow, 4-9, 2014)

2. M.A. Babintseva, Young scientist, 18, 61-65 (2014)

3. A.V. Voronkov, I.S. Belyaev, A.Yu. Dorokhin, A.N. Kandabar, Modern problems of science and education, 5 (2017)

4. E.A. Garanin, Pedagogico-psychological and medico-biological problems of physical culture and sport, 10(3), 29-37 (2015)

5. N.A. Grankin, Collection of scientific-methodical articles, (Nizhny Novgorod Higher Military-Engineering Command School, Kstovo, 65-70, 2012)

6. N.A. Grankin, Collection of articles Tyumen Higher Military -Engineering Command School, 13, 74-76 (2013)

7. I.N. Ibragimov, Z.M. Kuznetsova, A.S. Kuznetsov, Proceedings of the First International Volga Region Conference on Economics, Humanities and Sports (FICEHS 2019) (Atlantis Press, Paris, France, 2020)

8. I.N. Ibragimov, A.V. Ryabchuk, IV Pedagogical lections, dedicated to professor S.I. Zlobin (Tyumen, 94-97, 2018)

9. V.L. Karpman, Z.B. Belotserkovskiy, I.A. Gudkov, Testing in sports medicine (Medicine, Moscow, 1988)

10. V.B. Rubanovich, The basis of medical control during physical culture lessons (Yurayt, Moscow, 2019)

11. N.N. Sadiev, S.G. Nagovitsyn, Pedagogico-psychological and medico-biological problems of physical culture and sport, 1(30), 84-92 (2014)

12. Yu.A. Tsagarelli, System psychological diagnostics “Activatiometer” device (Institute of Management, Economics and Law, 
Kazan, 2004)

13. Z. Kuznetsova, A. Kuznetsov, I. Mutaeva, G. Khalikov, A. Zakharova, Proceedings of the $3^{\text {rd }}$ International Congress on Sport Sciences Research and Technology support (SCITEPRESS, 156-160, 2015) 